Article

\title{
Conditions under Which Trickle-Down Effects Occur: A Realist Synthesis Approach
}

\author{
Luke R. Potwarka ${ }^{1}$ and Pamela Wicker ${ }^{2, *(D)}$ \\ 1 Department of Recreation and Leisure Studies, University of Waterloo, 200 University Avenue West, \\ Waterloo, ON N2L 3G1, Canada; lrpotwarka@uwaterloo.ca \\ 2 Department of Sports Science, Bielefeld University, Universitätsstraße 25, 33615 Bielefeld, Germany \\ * Correspondence: pamela.wicker@uni-bielefeld.de; Tel.: +49-521-106-12994
}

Citation: Potwarka, L.R.; Wicker, P. Conditions under Which Trickle-Down Effects Occur: A Realist Synthesis Approach. Sustainability 2021, 13, 69. https://dx.doi.org/10.3390/su1301 0069

Received: 26 November 2020 Accepted: 18 December 2020 Published: 23 December 2020

Publisher's Note: MDPI stays neutral with regard to jurisdictional claims in published maps and institutional affiliations.

Copyright: () 2020 by the authors. Licensee MDPI, Basel, Switzerland. This article is an open access article distributed under the terms and conditions of the Creative Commons Attribution (CC BY) license (https:/ / creativecommons.org/ licenses/by/4.0/).

\begin{abstract}
Policy makers often legitimize bids for major sport events and public funding of elite sports by trickle-down effects, suggesting that hosting events, sporting success, and athlete role models inspire the population to participate themselves in sport and physical activity. According to previous review articles, empirical evidence of trickle-down effects are mixed, with several studies citing marginal or no effect. The purpose of this study is to apply a realist synthesis approach to evaluate under which conditions trickle-down effects occur (i.e., what works for whom under which circumstances?). Using rapid evidence assessment methodology, 58 empirical articles were identified in the search process and critically analyzed through the lens of realist synthesis evaluation. The analysis identified six conditions under which trickle-down effects have occurred: Event leveraging initiatives, capacity of community sport to cater for new participants, live spectating experiences, consumption possibilities on television or other media, and communities housing event venues. The findings have implications for the sustainability of sport policy decisions and public finance, as the likelihood of trickle-down effects increases with integrated planning and sustainable spending related to the above six conditions.
\end{abstract}

Keywords: demonstration effect; sport participation legacy; sport event; evaluation

\section{Introduction}

Bids to host elite international sport events often point to trickle-down effects (TDE) as one of the benefits associated with staging the event [1]. These effects refer to the inspiring role of elite sport including an event's capacity to increase sport and/or physical activity (PA) levels within host populations [2]. TDE are often employed as one argument to legitimize the spending of public money to support these events ex ante or to finance elite sport programs. To this end, claims of TDE can be used by event and elite sport stakeholders (e.g., governments and policymakers) to position events and elite sports as having positive and sustainable social impacts in host communities [3]. For instance, examples of TDE rhetoric from the London 2012 Olympic Games bid include: “ . . the Olympics will be the catalyst that inspires people of all ages and all talents to lead more active lives" [4] (n.p.); and "... [if London hosts the Olympics] grassroots participation will be boosted. An already sports-mad nation would get fitter and healthier" [5] (p. 2). Outcomes of TDE can be measured in terms of new participants in a sport or PA, an increase in participation frequency, participants returning to a sport after a long hiatus, or participants switching from one sport/activity to another [2].

To date, empirical evidence of TDE is mixed, with several studies reporting minimal or no changes in post-event participation [6]. These findings have led some researchers to dismiss claims of TDE, arguing that there is no reliable evidence to support their existence. Weed [2], for example, stated that there is "no reliable evidence to indicate that any Games staged to date had raised participation in the host community" (p. 7). Indeed, sport researchers are beginning to critique this area of inquiry in terms of both theory 
and methodology. For instance, researchers have argued that studies of TDE tend to be atheorectical, and not underpinned by any explanatory theory of behavioral change [7-9].

Additionally, many previous investigations of TDE employ cross-sectional research designs, which are unable to demonstrate causal links between the event and subsequent changes in participation - an issue that has been stressed by several scholars already [10-12]. Finally, extant TDE literature tends to draw conclusions from large-scale secondary mass participation data from adult populations (e.g., [13-16]). Collectively, the methodological research designs and the level of detail in the data might hinder the identification of TDE, which require a more nuanced analysis. Given these deficiencies in the literature, we argue that the difficulty of identifying TDE might often be rooted in the research designs and the level of detail in the data. Thus, it is not surprising that several researchers have searched for empirical evidence of TDE, but many have been unable to support their existence in the empirical analysis.

However, the question of the "existence" of TDE may be far more nuanced than simply claiming they do or do not exist. We argue that it is time for researchers to temper the debate about the "existence" of TDE, and instead focus their efforts on investigating the mechanisms and conditions by which elite sports in general, and specifically sport events, are most likely to bring about the desired participation impacts [5]. Importantly, participation includes sport and PA as many studies have not distinguished between these two participation categories. The resulting evidence in terms of sport and/or PA effects can help set expectations, assess financial investments, and guide legacy related strategies. In other words, drawing conclusions about the existence of TDE by scanning only population-level national participation data may be masking the full reach and scope of the phenomena. In our view, research approaches to TDE need to be much more nuanced, granular, coordinated, and rigorous. To this end, researchers are beginning to raise the question: Are we looking for evidence of TDE in the "right" places?

We advance the position that TDE research can benefit greatly from adopting a realist synthesis theoretical approach to evaluation. A realist synthesis uses a wide range of evidence to identify underlying causal mechanisms and explore how they work under what conditions, answering the question 'what works for whom under what circumstances?' rather than 'what works?' [5]. In this way, increased sport and PA levels associated with elite sport and an international sport event may be best understood as a result of the interaction of a particular combination of circumstances. Hence, using a realist synthesis approach to evaluation, the purpose of the current study was to identify salient mechanisms and conditions associated with the existence of TDE.

Identifying and understanding these conditions is important for legitimizing public spending and guiding investments into elite sport programs and for sport events. In recent years, the public has increasingly scrutinized public spending on sports in these areas (e.g., $[17,18])$. For example, the numerous failed referenda for hosting Olympic Games are testimonies of this scrutiny and the population across Western countries questioning spending on elite sport and its hallmark events (e.g., [19,20]). Hence, it is important for sport policy makers to have tangible evidence on TDE, which allows documenting that the investments yielded positive social outcomes and can be considered sustainable, meaning that an outcome is left after the respective event or sport was delivered. Hence, providing evidence on sport participation legacies of elite sports and sport events will help justify public spending in these areas and guide sport policy directions.

In addition to legitimizing public spending, the link between government decisions and sport participation/PA levels in the population should not be neglected [21]. Drawing on studies examining government quality, the empirical evidence clearly shows that higher government quality is associated with higher sport participation and PA rates at both the national and regional level (e.g., [21-23]). One facet of government quality is government effectiveness, essentially meaning that governments should deliver the desired outcomes. Such effectiveness is also relevant to elite sports and sport events where governments suggest the occurrence of TDE in sport policies and bid documents for events. Previous 
research has not only identified a positive effect of government quality as a whole on individuals' sport participation (e.g., [21,23]), but also a positive effect of government effectiveness on PA rates [22]. Hence, understanding the conditions and factors that contribute to the sustainability of public investments and sport policy decisions is also important from the perspective of government quality.

\section{Theoretical and Conceptual Framework}

\subsection{Trickle-Down Effects}

Following Weed [2], TDE are processes by which "people are inspired by elite sport, sports people or sports events to participate themselves" (p. 4). Specifically, TDE are thought to be linked to event hosting (e.g., [16]), sporting success (e.g., [24]), and role modelling (e.g., [12]). Hence, TDE include these three facets, which can be present separately or jointly.

While event hosting is intuitive from a conceptual perspective, the concepts of sporting success and role models need clarification. Sporting success refers to winning medals in sporting competitions, winning cups or championships, or achieving specific ranks in competitions. Depending on the sport and country, different understandings exist in terms of what type of sporting achievement qualifies as success. For example, while only winning titles was considered sporting success in a study on German football (e.g., [12]), a Flemish study on Olympic sports considered winning Olympic medals and achieving ranks until position eight as sporting success [24], meaning that qualification to the final round of eight is perceived as a success already. Hence, the understanding of what qualifies as sporting success can differ across studies.

The concept of role models has been widely discussed in previous research. The literature agrees that role models share at least two characteristics (e.g., [25-28]; for a more detailed conceptual discussion of role models see [12]. These characteristics are outstanding achievement and perceived similarity yielding a desire to change behavior. Starting with outstanding achievement, a role model is successful in an area the observing individual cares about [28]. Applied to sport, role models are typically characterized by outstanding sporting achievements in their sport (e.g., [11,12]. However, not only sporting achievements are a necessary condition for someone to qualify as a role model, because, in this case, role models would not be conceptually distinct from sporting success and every successful athlete would be considered a role model, which is not case.

The second characteristic of role models addresses this point as it relates to a perception of similarity between the observing individual and the athlete of interest [12]. The observing individual detects some similarities that yield to a desire to change his/her behavior by copying or imitating the role model [26]. Hence, role models have the capacity to influence individuals' behavior and decision-making [25]. The desire for imitation does not only come from athletes' on-field performance, but also to attributes and behavior off-the-field, such as charisma, social engagement, appearance, and personality [11,12,29].

The TDE literature also distinguishes between inspirational and motivational effects. While inspirational effects refer to elite sports turning inactive individuals to sport participants or club members (e.g., [10,12]), motivational effects include behavioral changes within already active sport participants, such as increasing the frequency of participation, changing the types of sports, or changing the position/role within one sport [23,30].

A concept related to TDE is sport participation legacy, which is often used as a synonym in studies examining different types of event legacies (e.g., [31]). A slightly different concept is the festival effect, which refers to positive experiences that new participants develop when engaging in sport and PA, such as enjoyment, social connections, and community spirit [32]. Hence, festival effects have often been examined in conjunction with TDE and are critical to the sustainability of TDE (e.g., [32,33]). 


\subsection{Realist Synthesis Evaluation}

Elite international sport events such as the Olympic and Paralympic Games have been conceptualized as public health interventions to increase population-level PA [34]. A realist synthesis evaluation begins with identifying the underlying theory behind a program or intervention [35]. This theory provides explanations of how the program or intervention will influence behavior [35]. It is possible for a program or intervention to work in one context, but not in another [35]. Within a realist synthesis evaluation, the success of a program or intervention is dependent upon a particular combination of contexts and mechanisms [36].

From this perspective, outcomes of TDE (e.g., increased sport or PA participation) are best understood as a result of the interaction of a particular combination of circumstances. In other words, the aim of a researcher employing a realist synthesis approach to evaluation is to identify the mechanisms and conditions necessary for an intervention (e.g., an elite international sport event) to produce the desired outcomes, such as increased sport/PA participation [35]. Therefore, by reviewing the best available scholarly evidence, we seek to produce a series of mechanisms and conditions, by which elite sports and international sport events might result in TDE. Consistent with our realist synthesis approach, we hope to provide insights into how TDE work, for whom, and under what circumstances [35,36].

\section{Methods}

\subsection{Rapid Evidence Assessment}

Collins et al. [37] outline a typology of different methods to produce reviews of the literature. Existing methods range from literature reviews over quick scoping reviews, rapid evidence assessments, full and multi-arm systematic reviews to a review of reviews, with the time and cost required to perform such a review increasing from the former to the latter. Similarly, the level of critical appraisal and the breadth or the search procedure increase from simple literature reviews to a review of reviews [37].

In the present study, existing evidence on the TDE was gathered using rapid evidence assessment methodology, which represents one form of evidence review that lies between a quick scoping review and a systematic review in terms of rigor of assessment. Within a rapid evidence assessment, the available evidence on a topic is identified, summarized, and critically appraised [37]. This type of review uses principles of a systematic review [38] and has been applied in existing sport research summarizing the available literature on monetary valuation of intangibles [18].

\subsection{Literature Search and Analysis}

The critical analysis of the literature was preceded by a search process for empirical studies examining TDE. This search process used a consistent search strategy in the databases SPORTDiscus, Medline, Springer Link, Google Scholar, Wiley Online Library, DOAJ, and JSTOR. The following keywords were entered in the search function-alone and also in combination with 'sport': Trickle-down effect, inspirational effect, sport participation legacy, demonstration effect, 'Boris Becker effect', and pyramid metaphor. The literature search was conducted in September 2020.

Altogether, the search yielded 58 empirical articles published in English in peerreviewed journals. Moreover, another five theoretical investigations [5,7,39-41], five review articles [6,34,42-44], and a number of project reports (e.g., [2]). These are not considered in the present study because the focus is on empirical evidence and, thus, only empirical papers are considered. In line with the rapid evidence assessment and the realist synthesis approach, the 58 empirical articles were subject to critical appraisal. Contrary to existing review articles, the empirical evidence was analyzed through the lens of a realist synthesis approach, aiming to identify the conditions under which TDE occur. 


\section{Results and Discussion}

\subsection{Quantitative Overview of TDE Research}

This section gives a quantitative overview over the studies included in the rapid evidence assessment. Specifically, it summarizes the years of publication of TDE studies (Figure 1), the countries where empirical TDE studies were conducted (Figure 2), the specific event or elite sport context of those TDE studies (Figure 3), the facet that was the focus of these studies (i.e., success, hosting, or role models; Figure 4), and the type of method or data employed by them (Figure 5). The section closes with an overview of the conditions under which TDE were found to occur (Figure 6). Since some studies included more than one country, event, or facet, or identified more than one condition, the percentages of the categories in Figures $2-4$ and Figure 6 add up to more than 100\%.

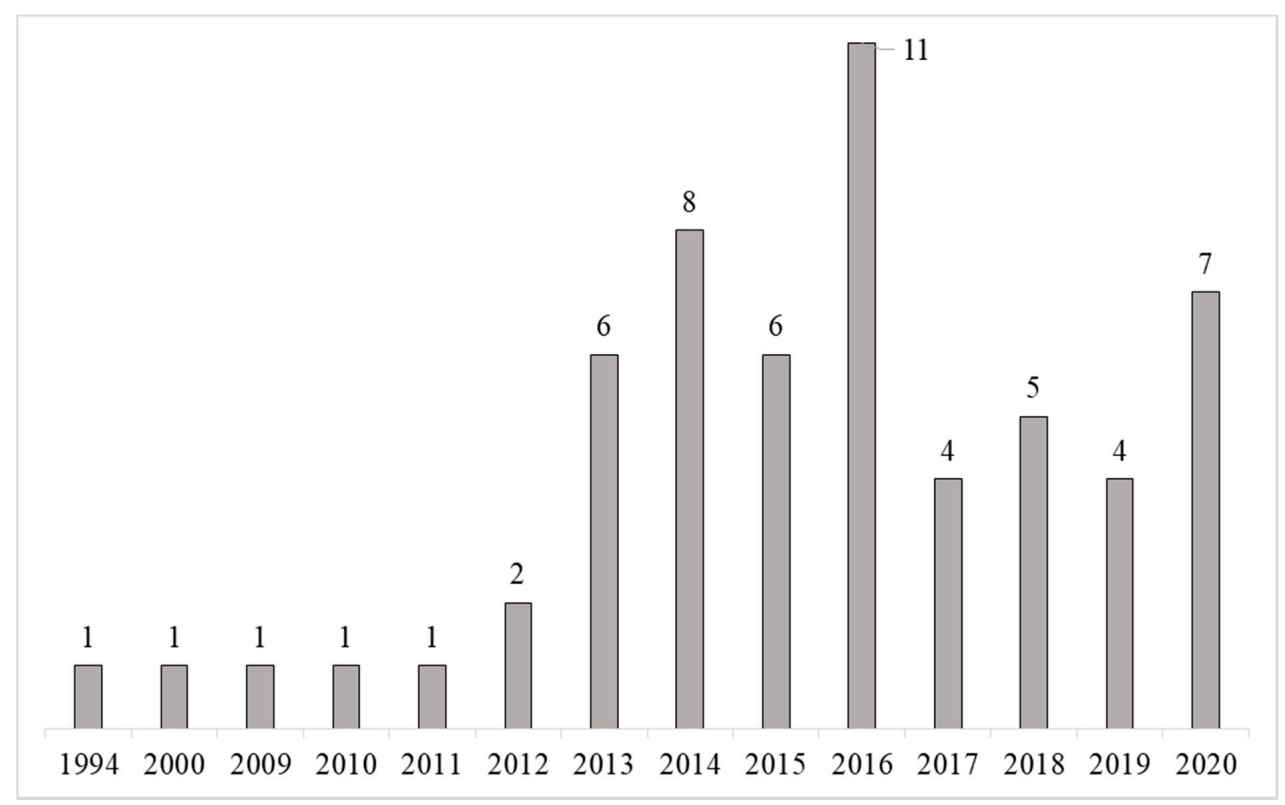

Figure 1. Overview of trickle-down effect (TDE) studies by year of publication (number of studies).

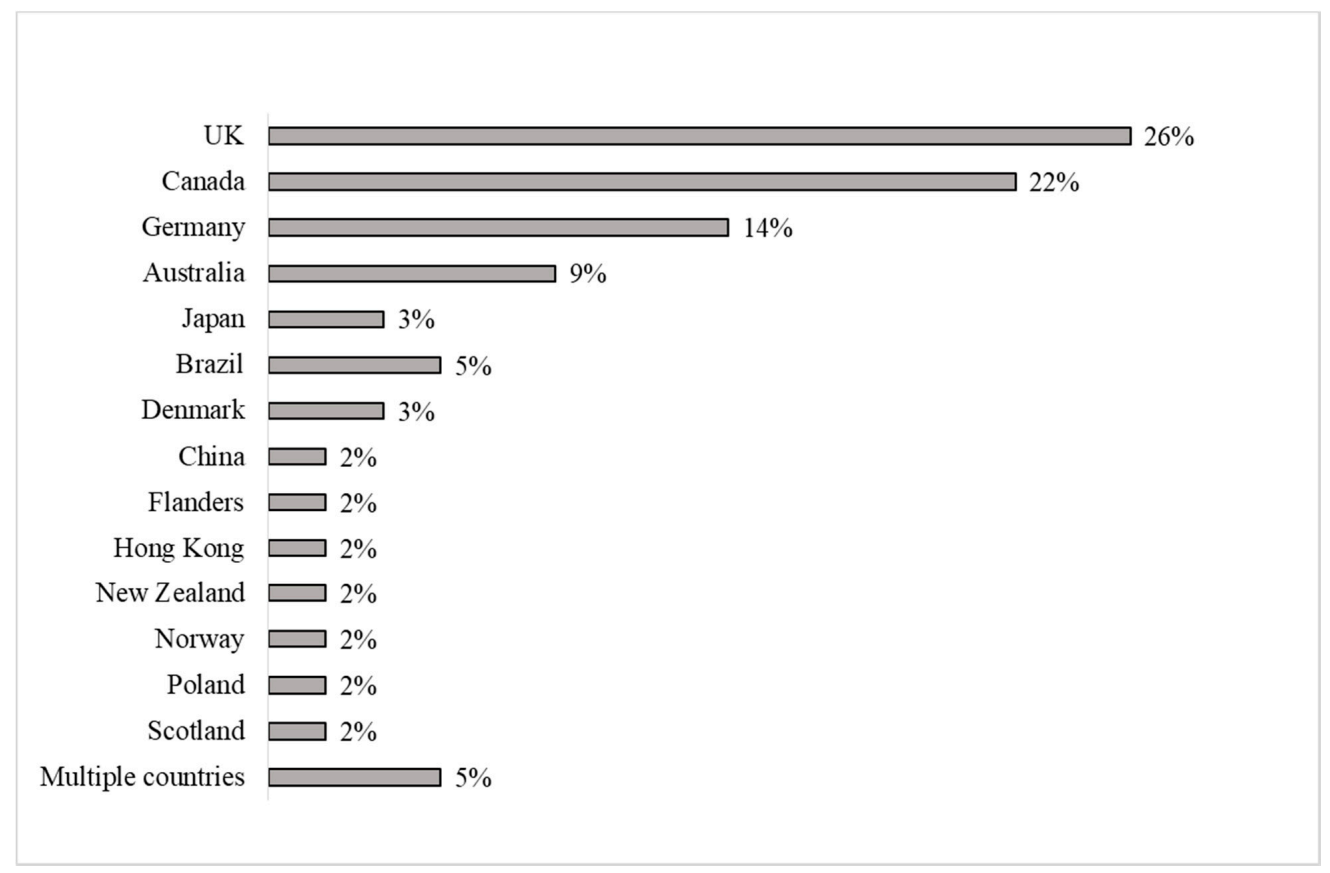

Figure 2. Overview of countries of TDE research (share of studies in \%). 


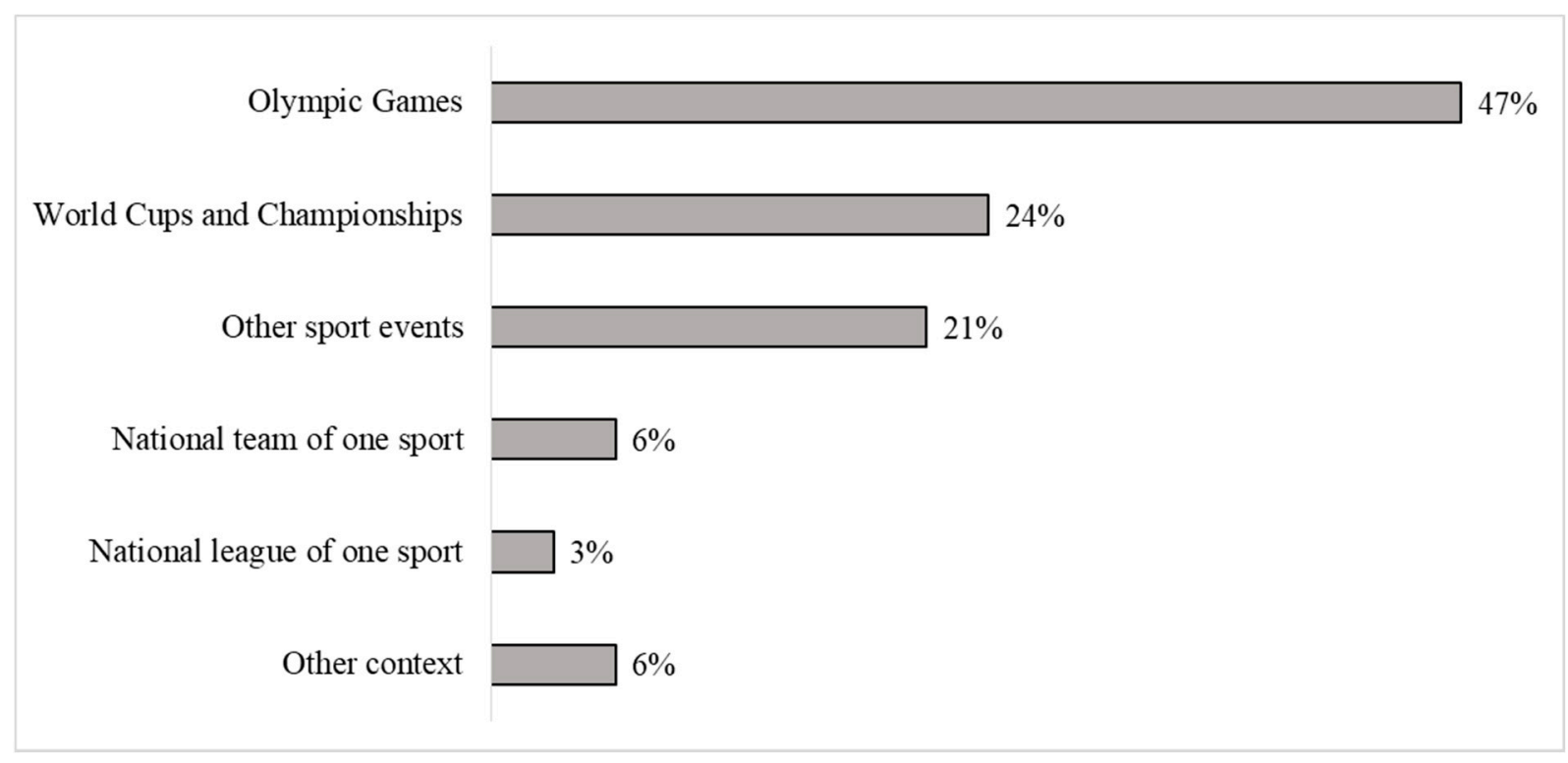

Figure 3. Overview of the different contexts of TDE research (share of studies in \%).

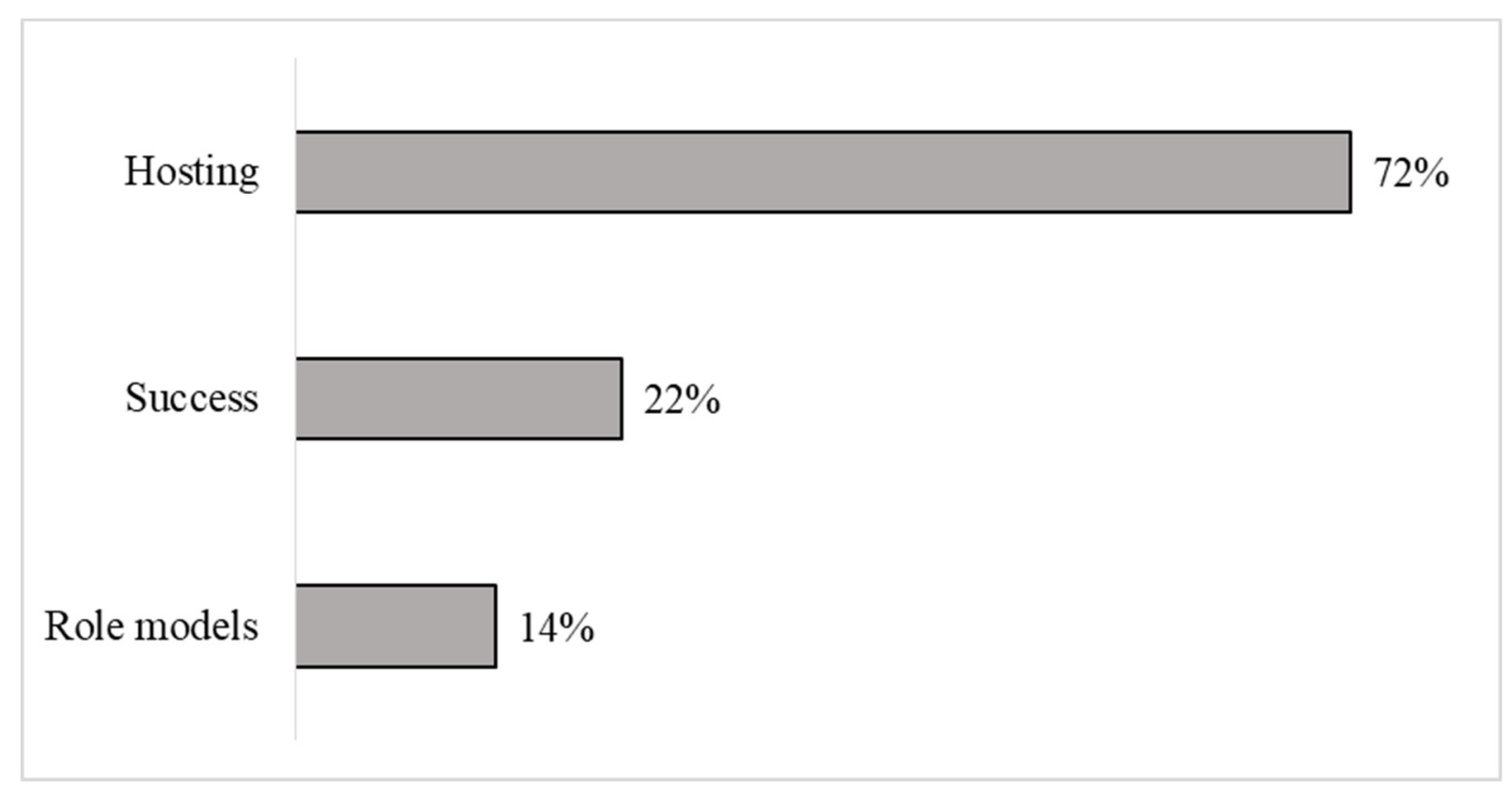

Figure 4. Overview of TDE facets examined in previous research (share of studies in \%). 


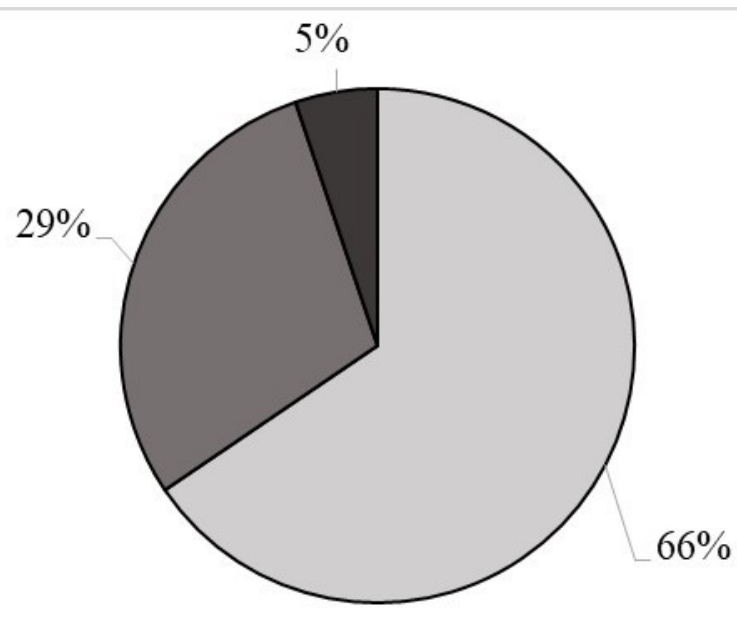

$\square$ Quantitative $\quad \square$ Qualitative $\quad \square$ Quantitative and qualitative

Figure 5. Overview of data/methods employed in TDE research (share of studies in \%).

Event leveraging initiatives

Capacity of community sport

Youth populations

Live spectator experiences

Consumption possibility

Communities housing event venues

No specific condition

No TDE

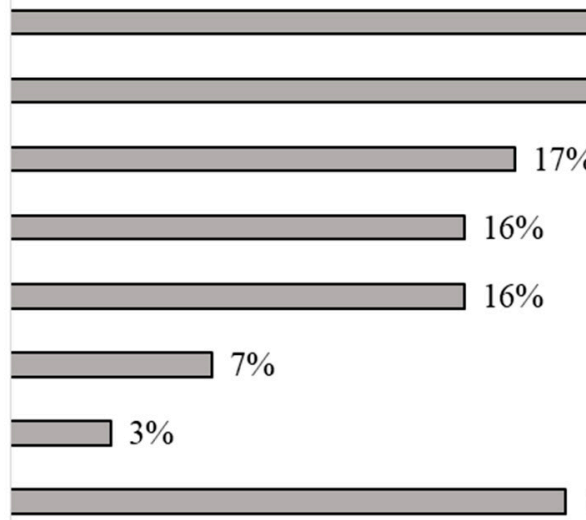

$19 \%$

\section{$7 \%$}

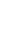

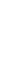

$24 \%$

$22 \%$ 
Australia (9\%) have been conducted in relation to the 2000 Sydney Games (e.g., [51]) and other major sport events held in this country, such as the 2003 Rugby World Cup (e.g., [52]) and the 2006 Melbourne Commonwealth Games (e.g., [53]). Hence, TDE research is in most cases closely tied to hosting major international sport events in the respective country.

Figure 3 displays the context of TDE research. It shows that almost half of all studies $(47 \%)$ were conducted in the context of the Olympic Games. World Cups and Championships attracted $24 \%$ of TDE research and other sport events another $21 \%$. Only a small share of TDE studies was performed in non-event contexts, such as national teams or leagues. Overall, this summary suggests that most TDE is tied to specific events.

Figure 4 presents the TDE facet that was investigated in previous research. Hosting a specific sport event was the most frequently studied facet $(72 \%)$, followed by sporting success $(22 \%)$ and role models (14\%). Given the strong focus on event contexts, studying the role of hosting is an apparent focus of TDE studies. Sporting success, although applicable to sport events not hosted in the country of interest, has attracted less research attention. Only a few studies examined the inspirational effect of role models. This relative scarcity might result from the challenges of adequately measuring role models and from the inherent difficulty of disentangling sporting success and role models empirically. Only one study has investigated all three facets so far [11].

Figure 5 summarizes that types of methods or data employed in previous TDE research. With $66 \%$, most studies used quantitative approaches, like survey data or secondary data. Altogether, $29 \%$ of studies drew on qualitative approaches, such as interviews, focus groups, or document analysis. Only $5 \%$ of studies combined both approaches.

Figure 6 provides a quantitative overview over the conditions under which TDE occur. The figures also includes the share of studies reporting no TDE. This share is $19 \%$, suggesting that no empirical evidence for TDE was found in only about one out of five studies. Hence, previous statements stressing that empirical evidence for TDE is scarce or difficult to find cannot be supported by these figures. However, the present evaluation also suggests that TDE tend not to occur for the whole population across a country, but that specific conditions must be met.

Specifically, the realist synthesis analysis identified the following six conditions under which TDE have been evident: Event leveraging activities (e.g., [54-56]); capacity of community sport to cater for new participants (e.g., [47,57]; youth populations (e.g., [11,51,52]); live spectator experiences (e.g., [58,59]); consumption possibility of sports/events in the media or on television (e.g., [24,50]), and communities housing event venues (e.g., $[15,16,60])$. The most frequently identified condition was event leveraging activities (24\%), followed by the capacity of community sport to cater to new participants $(22 \%)$ and the presence of youth populations (17\%). Experiences regarding live spectating were found to be equally relevant as consumption possibility of events or athletes on television or other media $(16 \%$ each). Communities housing event venues only represented a relevant condition in $7 \%$ of the TDE studies, while no specific condition could be identified in $3 \%$ of the studies. The next sections present and discuss these six conditions in detail.

\subsection{Event Leveraging Activities}

The potential for TDE is more likely to occur in conjunction with carefully planned and executed event leveraging strategies (e.g., [61-63]). Leveraging is underpinned by the idea that increased participation levels are more likely to result from the combined influence of staging an event and the implementation of interventions designed to promote sport opportunities [5]. Many researchers argue that providing spectators with opportunities to try the sport on display can help ensure sport events have a behavioral impact beyond just influencing people's post-event intentions to participate $[44,54,64]$. Researchers argue that TDE are relevant to people, but the simple hosting of the event does not yield changes in attitudes or sport participation behavior without extra efforts such as leveraging initiatives [33]. 
Nevertheless, sport event stakeholders often fail to design, implement, and evaluate leveraging programs that encourage people to try a new sport [65]. Concrete event leveraging strategies are often absent as it is unclear who is responsible for implementing and executing them [62]. Given this deficiency, there have been increased calls in the TDE literature for research to examine the impacts that exposure to particular event leveraging initiatives deployed before, during, or after events has on stimulating sport participation.

The literature has advanced several event leveraging activities. The most specific one is the provision of a voucher for testing the sport of track cycling following the 2015 Pan Am Games (e.g., [54,66]). Potwarka et al. [54] employed an experimental design to test the efficacy of distributing vouchers in stimulating post-event trial participation among adults in the sport of track cycling. The authors concluded that the voucher was a powerful tool to promote track cycling, especially in motivating those with little or no intentions to participate. Moreover, participation in the trial and a structured program following the voucher lead to increases in memberships in track cycling [66].

For TDE to occur and event leveraging initiatives to be effective, sustainable and integrated planning is required. At the policy level, long-term planning and policies for sport participation and infrastructure are required [55]. This includes the host region, but can also go beyond. For example, a policy initiative was effective in increasing sport participation before the 2012 London Games in a non-hosting region [67]. Generally speaking, the developed strategies need to be long-term in nature and all event stakeholders should be included, including the local community, sport organizations, local clubs, coaches etc. Such integrated planning requires a coordination of efforts by governments and event organizers [68].

Existing research has provided examples of integrated efforts or lack thereof. For example, when sport events are hosted, they need to be integrated in the marketing mix of local and national sport organizations [64]. Integrated planning also requires communication efforts between national governing bodies and grassroots sports organizations [49]. There are also examples where the implementation of action steps for leveraging activities was hindered by competition and distrust among local clubs and sport organizations being overburdened by the requirements of organizing competitions, leaving fewer resources for event leveraging initiatives. Moreover, tensions can arise between the host city aiming to promote the city rather than the sport [65]. Overall, establishing grassroots participation programs were considered an effective tool for TDE [49]. Such programs are closely tied to coaches and PA professionals, which also need to be educated about leveraging initiatives and possible TDE [56]. Hence, despite many sport events catering for elite sports and having international reach, their TDE are closely linked to capacities and efforts at the grassroots level which are discussed next.

\subsection{Capacity of Community Sport to Cater for New Participants}

Sport participation, especially participation organized in grassroots sport clubs, can only increase when sport organizations have the capacity to cater for new participants $[69,70]$. Even though grassroots participation programs were considered most effective for facilitating the occurrence of TDE [49], they need to be designed and implemented, often requiring additional financial, human, and infrastructure resources [47,65,71]. Moreover, the local population must be informed about these new sport opportunities [59]. Hence, building sport club capacity and ensuring visibility of clubs during the event represent critical factors for TDE [72].

With resource scarcity representing a challenge for the development of community sport clubs [73], investment into sport clubs and facilities are required to address these capacity issues and increase their resource base in terms of coaches, facilities etc. [52,57]. Not only are financial resources required for TDE, but also integrated planning efforts for the type of sport infrastructure that is needed in community sport to cater for potential new participants [55]. Otherwise, sport clubs' insufficient human and physical resources were found to hinder the provision of grassroots sport programs and the occurrence of TDE [65]. 
Moreover, for TDE to be sustainable, public funding needs to be long-term. Previous research has documented that funding removal for community sport hindered TDE [47]. Once community sport programs are in place, information about those sport opportunities is critical [59], highlighting the need of communicating these increased capacities at the grassroots level.

In the literature discussing the need for increased capacities in grassroots sports, one target group is mentioned frequently, i.e., children and youth. Especially the capacity to cater for new participants among children and youth is relevant for TDE to unfold [74]. Previous research has highlighted the role of investments to facilitate children's participation [52] and the importance of coaches and leaders in clubs for increasing children's participation [57]. These aspects are closely linked to the next condition.

\subsection{Youth Populations}

A number of studies have documented that TDE may be more pronounced within youth populations (e.g., [52,53,60,75]). For example, [60] reported that the long-term impact of the 1964 Tokyo Olympic Games was more prominent among those who were youth at the time of the event compared to older generations. In another study, a slight increase in participation was only documented for children in Olympic sports following the 2000 Sydney Games [51]. Likewise, the registrations in rugby increased following the hosting of the 2003 Rugby World Cup, especially for juniors [52]. Moreover, younger people were more likely to spend more time participating or start new activity following the 2006 Melbourne Commonwealth Games [53]. Furthermore, [75] found that, compared to people employed full-time, student populations were more likely to participate in moderately intense activities following the London 2012 Olympic Games. One explanation for these findings is that as people age, they may give more priority to areas of education, work, and family than to nonworking and sport-related activities [60].

Not only hosting of events, but also sporting success and athlete role models were found to have an inspirational effect especially for children and youth. For example, following Australia's qualification for the 2006 World Cup (which was considered a success for Australia), a positive trend in football participation of children and youths was observed [74]. In Danish handball, a positive effect of the success of the men's and women's national team on children's memberships was documented, while for adults, even a few negative effects were evident [76].

Previous research has highlighted that sporting role models are especially important for children and youth. For example, related to the 2012 London Summer Games, the inspiration by athlete role models supported the occurrence of TDE [77]. Moreover, while home events were found to have a positive effect on club memberships of adults and youths/children in Germany in the year of event, role models only had an inspirational effect on youths/children, not on adults [11]. Likewise, when the players of the male national football team are perceived as role models, a positive effect on the development of youth club memberships and football teams in Germany were evident [12]. The latter study also points to gender differences in the measurable inspirational effects of role models, with the successes of the female national team and female role models mostly having negative effects on youth teams and memberships. These gender differences were explained with the concept of gendered heroism [78], indicating that the attributes assigned to sporting heroes have a lower fit with the female gender role than the male gender role. Accordingly, girls and young women were more likely to select male role models in sport [12].

\subsection{Live Spectator Experiences}

Several studies suggest that live spectating facilitates the occurrence of TDE (e.g., $[10,58,59,72,79-81]$. Specifically, [10] hypothesized that what people think about, and what they feel while immersed in a spectator experience, can have a profound influence on post-event decisions to participate. Fantasizing being an athlete participating in the action; intense absorption in the spectator experience; critically judging the performance 
and skills of athletes; and appreciating the grace and beauty of the sport itself, can influence the propensity to feel inspired while consuming live sport events [10]. Feelings of inspiration, in turn, can positively influence the formation of a behavioral intention, and reduce perceptions of physical inadequacy that may discourage participation [10]. An affective state of inspiration has been characterized as an appetitive motivational state, which involves feelings of energy, confidence, and enthusiasm that can result in the attainment of post-event participation goals [82].

A number of studies have documented positive associations between live spectating and TDE. For example, spectator experiences at the 2015 Pan Am Games that evoked intense feelings of being inspired while immersed in the event were found to represent salient mechanisms involved in decisions to try a new sport on display, i.e., track cycling [81]. Moreover, live spectating was found to yield different types of increases in sport participation behavior, i.e., initial, sustained, and lagged effects [70]. In addition, spectating at a half marathon in Poland had a positive effect on people's willingness to participate in sport and running after the event [79]. Likewise, inspiration from spectating at the 2002 Football World Cup was found to have a positive effect on immediate football participation [58].

Concerning the two types of TDE, the literature suggests that especially motivational effects occur as a result of live spectating experiences. For instance, event attendance was associated with increases in sport participation, but more so for already active participants [80]. In another study, spectators indicated that they planned to increase their participation level, and the planned increases were higher for already active participants [59]. Moreover, following and spectating professional triathlon and attaching importance to the sport yielded more minutes of weekly participation in the sport of triathlon [83]. In tennis, individuals reporting a higher relevance of professional tennis were found to spend more time playing tennis themselves and had higher tennis-related expenditure [84].

\subsection{Consumption Possibility of Sports/Events in the Media/on Television}

A number of researchers have argued that TDE are more likely to occur within populations of spectators who are already consumers of the respective sport (e.g., [60,85]). Thus, availability of a sport on television (TV) or in other media (e.g., newspaper, Internet) is also relevant for TDE, not only individuals' physical attendance in the stadium. Regular consumption of a sport creates knowledge of the sport and the involved athletes and/or teams [86], which is important to forming behavioral intentions of sport participation [83]. Specifically, fans of a sport or those who have knowledge of a sport before watching events were more likely to form post-event intentions to participate [81].

Such knowledge can be subsumed under the concept of consumption capital which is, in general, generated through the repetitive consumption of similar goods [87]. Applied to sport, sport-specific consumption capital is generated through the repetitive consumption of a particular sport on TV and in other media, yielding a stock of knowledge about rules, teams, athletes etc. This sport-specific consumption capital is necessary to understand the sport and enjoy the spectating experience [86]. Like other forms of capital (e.g., human capital, social capital), consumption capital needs to be built over a longer time period. This requirement can represent a problem for many Olympic sports, which are less frequent on TV during the Olympiad, meaning the four-year time period between two Olympic Games. Hence, consumers have a lower chance of building consumption capital in these sports, ultimately lowering the likelihood of TDE to occur from watching these sports. Put differently, as popular sports are more frequently shown on TV and can, therefore, be watched by many consumers, these sports are more likely to generate TDE when major events are held.

These theoretical patterns are also reflected in the empirical evidence on TDE. For example, a positive correlation between sporting success and club memberships was only documented in sports that are popular in Belgium (i.e., athletics, gymnastics, judo, tennis) [24]. Tennis is also a popular sport in Germany, explaining why following tennis on TV is associated with increasing minutes of participation [83]. 
In many countries, football is frequently shown on TV. Accordingly, watching successes of the male national football team increases football participation at the grassroots level [74]. A similar effect was evident for watching games of the 2002 Football World Cup on TV [58]. Likewise, watching successes of the German national football team on TV was found to increase the participation frequency of already active participants [30], supporting the motivational part of the TDE.

In Germany, especially the men's national football team and its players can be frequently consumed on TV. Hence, it is less surprising that only sporting successes (i.e., World Cup titles) of the men's team had a measurable inspirational effect on the number and growth rate of club memberships, football teams, and football clubs at the grassroots level. The sporting successes of the women's national team had no measurable impact, although this team won more titles than the men's team [12].

Olympic Games are broadcast in most countries across the globe. Accordingly, watching the Games on TV was also found to yield TDE in previous research. For example, young adults who were more physically active after the 2010 Vancouver Games expressed that they connected with their sport through engaged viewership [50]. Moreover, even rheumatology patients were motived to increase their amount of physical activity as a result of watching the 2012 London Games on TV [48].

\subsection{Communities Housing Event Venus}

TDE research often draws conclusions from analyses of national and provincial/ territorial-level participation data. Indeed, TDE-related data are rarely delineated or examined within local communities and neighborhoods that house event venues. Potwarka and Leatherdale's [16] concept of the "epicenter effect" suggests that when searching for evidence of TDE, researchers should first consider participation data at local and regional levels, and then move outward and consider data at provincial/territorial and national levels. If the analysis is approached this way, evidence of TDE might be greatest near venue locations.

An empirical example for such an epicenter effect is the study by [16] examining TDE in the context of hosting the 2010 Vancouver Olympic Games. The authors found no statistically significant changes in the rate of moderately active/active youth in Canada, or the province of British Columbia (BC) from pre-to-post event. However, at the regional level, their analysis revealed a significant increase in the rate of moderately active/active females from pre-event to post-event years in the local region of Richmond, BC. The authors noted that the municipality of Richmond was home to the newly constructed Olympic oval, which played host to a record number of medals for Canadian women speed skaters, and was open for public use post-event.

In another study on the Vancouver Games, these Olympics had almost no impact on sport participation except for the Vancouver area, suggesting that TDE were limited to the local community [15]. Further research on these Games indicated that that geographic proximity to the event venues affects control beliefs which, in turn, affect behavioral intentions to become more active as a response to the event [15]. On the contrary, geographic proximity to the event had no impact on sport participation in a study on the 1964 Tokyo Olympics. Specifically, living in the host region was insignificant, only belonging to the age cohort experiencing the 1964 Tokyo Games had a positive effect on individual' sport participation [60].

The role of geographic proximity is not only discussed in relation to TDE, but also when it comes to public support for hosting an event or the construction of sport facilities. On the one hand, some studies highlight proximity costs when residents want to shift the event or the facility away from their neighborhood (e.g., [88,89]. Other studies suggest that proximity to the event venues contributes to public support for the event because residents can enjoy the event festivities and atmosphere (e.g., [19,20]). The evidence for TDE showing proximity benefits supports the latter studies and suggests that increasing 
the number of potential host communities represents one way to increase the likelihood of TDE.

\section{Conclusions}

This study set out to identify conditions under which TDE have occurred in previous empirical research. It conducted a review of empirical studies using rapid evidence assessment methodology and critically analyzed them through the lens of a critical synthesis approach. Six conditions were identified, including event leveraging initiatives, capacity of community sport to cater for new participants, live spectating experiences, consumption possibilities on television or other media, and communities housing event venues. Hence, this review differs from existing reviews (e.g., [6,34,42,44]) providing little evidence of TDE as we take a more nuanced approach. Specifically, we have scanned the literature through the lens of 'what works, for whom, and under which circumstances'. The findings indicate that elite sport events, role models, and sporting success are not the panacea to increase sport participation and PA everywhere and for everybody, but that TDE occur under specific conditions in particular regions and for particular population groups.

The outcomes of this review have implications for government representatives and sport policy makers. They should be considered in bids for major sport events and in funding programs for elite sport. Rather than expecting nationwide TDE to occur automatically from hosting and event or from sporting success, planning initiatives need to be undertaken and resources need to be directed towards different areas (e.g., community sport, local sport facilities, human resources of local clubs) to facilitate the occurrence of TDE. Once a more nuanced approach is taken, the identified conditions help justify public investments into hosting events and funding elite sport programs. When events and elite deliver the outcomes sport that government representatives promise, these outcomes also help improve the perception of government effectiveness by the resident population, which is one facet of government quality [21,22]. Ultimately, the present study can help improve the sustainability of sport policy and public spending. It is important to note that the findings of our study may be subject to a publication bias. It is possible, for instance, that some research included in the present investigation may be been funded by political institutions, who may have influenced the findings in some way. That said, we attempted to limit the potential for such bias by considering only published peer-reviewed papers and no project/technical reports. Thus, the research analyzed in the current study was previously reviewed and critiqued for methodological rigor, thereby reducing the possibility that the evident results were affected by those who paid for the study.

The findings of this study set the scene for many directions future research can take. First, this work has identified six conditions from existing empirical studies that have been published already. As the body of research on TDE grows over the next years, further conditions will be identified along the way. One such condition could be the hometowns of Olympic medalists. Millions of people from outside host communities and around the globe tune in to watch athletes from their own communities compete for Olympic and Paralympic medals. Initial research by [90] reports statistically significant increases in PA levels among youth living in five (of 26) hometown health regions between the preand post-event period in relation to the 2012 London Olympics. People may perceive a special connection with elite athletes from their hometown because they share similar access to sport-related opportunities, coaches, and activity promoting infrastructure in the built environment. While this initial research is promising, further empirical evidence is required, as other research has found no effect of the number of medals won by athletes from a specific region [60].

Second, a more nuanced analysis of socio-demographic characteristics is necessary. Those studies providing a more distinct analysis have typically considered individuals' age and/or gender. Especially with respect to gender, further studies are required to better understand the role of residents' gender and the role of athletes' gender. Moreover, future research should examine the roles of other socio-demographic characteristics beyond age 
and gender, including race, ethnicity, culture, and ability/disability. Indeed, TDE research would benefit from more diverse and inclusive perspectives.

Third, many studies focused on positive TDE, meaning beneficial effects from elite sports and hosting events. However, there is also initial evidence of discouragement effects and negative effects (e.g., [91]), but not in all studies [80]. Relatedly, future research should study the impacts that negative role models (e.g., athletes using performance-enhancing drugs; athlete misconduct) and also sporting failure (e.g., [91]) have on individuals' sport participation behaviors. Since TDE can be an international phenomenon, not all role models are necessarily country specific as some athletes might be considered global role models (e.g., Michael Jordan, Serena Williams, Usain Bolt) who might inspire individuals beyond national boundaries. Studying the resulting TDE represents another area for future research.

Fourth, TDE research might be expanded to other sport stakeholders beyond active participants such as volunteers. Hence, future studies could build upon initial research by [92] identifying TDE from role models in refereeing on voluntary referees in German amateur football.

Fifth, for the sport policy and public finance debate, not only are TDE important to document, but also further beneficial outcomes or increased sport participation levels, such as increased spending (e.g., [84]). Hence, future research should estimate the monetary outcomes of increased sport participation levels, potentially relying on the estimation methods outlines by Orlowski and Wicker [18].

Author Contributions: Conceptualization, L.R.P. and P.W.; methodology, P.W.; formal analysis, P.W. and L.R.P.; writing—original draft preparation, P.W. and L.R.P.; writing—review and editing, L.R.P. and P.W. All authors have read and agreed to the published version of the manuscript.

Funding: This research received no external funding.

Institutional Review Board Statement: Not applicable.

Informed Consent Statement: Not applicable.

Data Availability Statement: This study is not based on data as it is a review article.

Conflicts of Interest: The authors declare no conflict of interest.

\section{References}

1. Faktenreihe München 2018. Financial Planning. Available online: https://www.dosb.de/fileadmin/Bilder_allgemein/ Veranstaltungen/Muenchen2018/Muenchen2018_Faktenreihe_Finanzplanungt.pdf (accessed on 1 June 2016).

2. Weed, M. The potential of the demonstration effect to grow and sustain participation in sport. In A Review Paper for Sport England; Centre for Sport, Physical Education and Activity Research (SPEAR): Canterbury Christ Church University, Canterbury, UK, 2009.

3. Potwarka, L.R.; Snelgrove, R. Managing sport events for beneficial outcomes: Theoretical and practical insights. Event Manag. 2017, 21, 135-137. [CrossRef]

4. Statement to the House of Commons. Available online: www.culture.gove.uk/Reference_library/Press_notices/archive_2003 /olympic_statement.htm (accessed on 1 February 2008).

5. Coalter, F. A Wider Social Role for Sport: Who's Keeping the Score? Routledge: New York, NY, USA, 2017.

6. Weed, M.; Coren, E.; Fiore, J.; Wellard, I.; Chatziefstathiou, D.; Mansfield, L.; Dowse, S. The Olympic Games and raising sport participation: A systematic review of evidence and an interrogation of policy for a demonstration effect. Eur. Sport Manag. 2015, 15, 195-226. [CrossRef]

7. Boardley, I.D. Can viewing London 2012 influence sport participation? A viewpoint based on relevant theory. Int. J. Sport Policy Pol. 2013, 5, 245-256. [CrossRef]

8. Potwarka, L.R. Exploring physical activity intention as a response to the Vancouver Olympics: An application and extension of the theory of planned behavior. Event Manag. 2015, 19, 73-92. [CrossRef]

9. Ramchandani, G.; Coleman, R.; Christy, E. The sport participation legacy of major events in the UK. Health Promot. Int. 2019, 34, 82-94. [CrossRef]

10. Potwarka, L.R.; Drewery, D.; Snelgrove, R.; Havitz, M.E.; Mair, H. Modelling a demonstration effect: The case of spectators' experiences at 2015 Pan Am Games' track cycling competitions. Leis. Sci. 2018, 40, 578-600. [CrossRef]

11. Weimar, D.; Wicker, P.; Prinz, J. Membership in nonprofit sport clubs: A dynamic panel analysis of external organizational factors. Nonprofit Volunt. Sect. Q. 2015, 44, 417-436. [CrossRef] 
12. Wicker, P.; Frick, B. The inspirational effect of sporting achievements and potential role models in football: A gender-specific analysis. Manag. Sport Leis. 2016, 21, 265-282. [CrossRef]

13. Craig, C.L.; Bauman, A.E. The impact of the Vancouver Winter Olympics on population level physical activity and sport participation among Canadian children and adolescents: Population based study. Int. J. Behav. Nutr. Phys. Act. 2014, $11,107$. [CrossRef]

14. Downward, P.; Dawson, P.; Mills, T.C. Sports participation as an investment in (subjective) health: A time series analysis of the life course. J. Public Health 2016, 38, e504-e510. [CrossRef]

15. Perks, T. Exploring an Olympic "legacy": Sport participation in Canada before and after the 2010 Vancouver Winter Olympics. Can. Rev. Sociol. Anthropol. 2015, 52, 462-474. [CrossRef]

16. Potwarka, L.R.; Leatherdale, S. The Vancouver 2010 Olympics and leisure-time physical activity rates among youth in Canada: Any evidence of a trickle-down effect? Leis. Stud. 2016, 35, 241-257. [CrossRef]

17. Könecke, T.; Schubert, M.; Preuß, H. (N)Olympia in Germany? An analysis of the referendum against Munich 2022. Ger. J. Exerc. Sport Res. 2016, 46, 15-24. [CrossRef]

18. Orlowski, J.; Wicker, P. Monetary valuation of non-market goods and services: A review of conceptual approaches and empirical applications in sports. Eur. Sport Manag. Q. 2019, 19, 456-480. [CrossRef]

19. Coates, D.; Wicker, P. Why were voters against the 2022 Munich Winter Olympics in a referendum? Int. J. Sport Financ. 2015, 10, 267-283.

20. Wicker, P.; Frick, B. NOlympia in Tyrol: Determinants of voting behavior in the referendum for the 2026 Innsbruck-Tyrol Winter Games. Int. J. Sport Financ. 2020, 15, 3-15.

21. Wicker, P.; Downward, P. Exploring spillovers between government quality and individual health production through sport and physical activity. Eur. Sport Manag. Q. 2017, 17, 244-264. [CrossRef]

22. Van Tuyckom, C. Macro-environmental factors associated with leisure-time physical activity: A cross-national analysis of EU countries. Scan. J. Public Health 2011, 39, 419-426. [CrossRef]

23. Wicker, P.; Downward, P.; Lera-López, F. Does regional disadvantage affect health-related sport and physical activity level? A multi-level analysis of individual behaviour. Eur. J. Sport Sci. 2017, 17, 1350-1359. [CrossRef]

24. De Bosscher, V.; Sotiriadou, P.; van Bottenburg, M. Scrutinizing the sport pyramid metaphor: An examination of the relationship between elite success and mass participation in Flanders. Int. J. Sport Policy Politics 2013, 5, 319-339. [CrossRef]

25. Basow, S.A.; Howe, K.G. Role-model influence: Effects of sex and sex-role attitude in college students. Psychol. Women Q. 1980, 4, 558-572. [CrossRef]

26. Gibson, D.E. Developing the professional self-concept: Role model construals in early, middle, and late career stages. Organ. Sci. 2003, 14, 591-610. [CrossRef]

27. Lockwood, P. "Someone like me can be successful”: Do college students need same-gender role models? Psychol. Women Q. 2006, 30, 36-46. [CrossRef]

28. Lockwood, P.; Kunda, Z. Superstars and me: Predicting the impact of role models on the self. J. Pers. Soc. Psychol. 1997, 73, 91-103. [CrossRef]

29. Deutschland braucht den Superstar. Die gesellschaftliche Bedeutung von Vorbildern im Profifußball. Available online: https://www.bundesliga.de/media/native/dokument/isbs_issue_4_deutschland_braucht_den_superstar.pdf (accessed on 20 April 2015).

30. Mutter, F.; Pawlowski, T. Role models in sports-Can success in professional sports increase the demand for amateur sport participation? Sport Manag. Rev. 2014, 17, 324-336. [CrossRef]

31. Thomson, A.; Cuskelly, G.; Toohey, K.; Kennelly, M.; Burton, P.; Fredline, L. Sport event legacy: A systematic quantitative review of literature. Sport Manag. Rev. 2019, 22, 295-321. [CrossRef]

32. Carter, R.V.; Lorenc, T. A qualitative study into the development of a physical activity legacy from the London 2012 Olympic Games. Health Prom. Int. 2015, 30, 793-802. [CrossRef] [PubMed]

33. Cleland, C.L.; Ellaway, A.; Clark, J.; Kearns, A. Was Glasgow 2014 inspirational? Exploring the legacy impacts of a mega-sport event via the theorized demonstration and festival effects. Sport Soc. 2020, 23, 810-831. [CrossRef] [PubMed]

34. Murphy, N.M.; Bauman, A. Mass sporting and physical activity events-are they "bread and circuses" or public health interventions to increase population levels of physical activity? J. Phys. Act. Health 2007, 4, 193-202. [CrossRef]

35. Pawson, R.; Tilley, N. Realistic Evaluation; Sage: London, UK, 1997.

36. Realist Evaluation. Available online: http:/ / www.communitymatters.com.au/RE_chapter.pdf (accessed on 7 November 2020).

37. The Production of Quick Scoping Reviews and Rapid Evidence Assessments. A How to Guide. Available online: https://assets.publishing.service.gov.uk/government/uploads/system/uploads/attachment_data/file/560521/Production_ of_quick_scoping_reviews_and_rapid_evidence_assessments.pdf (accessed on 20 August 2018).

38. Tranfield, D.; Denyer, D.; Smart, P. Towards a methodology for developing evidence informed management knowledge by means of systematic review. Br. J. Manag. 2003, 14, 207-222. [CrossRef]

39. Charlton, T. 'Grow and Sustain': The role of community sports provision in promoting a participation legacy for the 2012 Olympic Games. Int. J. Sport Policy Politics 2010, 2, 347-366. [CrossRef]

40. Girginov, V.; Hills, L. A sustainable sports legacy: Creating a link between the London Olympics and sports participation. Int. J. Hist. Sport 2008, 25, 2091-2116. [CrossRef] 
41. Veal, A.J.; Toohey, K.; Frawley, S. Sport participation, international sports events and the 'trickle-down effect'. J. Pol. Res. Tour. Leis. Events 2019, 11, s3-s7. [CrossRef]

42. Mahtani, K.R.; Protheroe, J.; Slight, S.P.; Demarzo, M.M.P.; Blakeman, T.; Barton, C.A.; Brijnath, B.; Roberts, N. Can the London 2012 Olympics 'inspire a generation' to do more physical or sporting activities? An overview of systematic reviews. BMJ Open 2013, 3, e002058. [CrossRef]

43. McCartney, G.; Thomas, S.; Thomson, H.; Scott, J.; Hamilton, V.; Hanlon, P.; Morrison, D.S.; Bond, L. The health and socioeconomic impacts of major multi-sport events: Systematic review (1978-2008). BMJ 2010, 340, c2369. [CrossRef] [PubMed]

44. Weed, M.; Cohen, E.; Fiore, J.; Mansfield, L.; Wellard, I.; Chatziefstathiou, D.; Dowse, S. Developing a physical activity legacy from the London 2012 Olympic and Paralympic games: A policy-led systematic review. Perspect. Public Health 2012, 132, 75-80. [CrossRef]

45. Hindson, A.; Gidlow, B.; Peebles, C. The 'trickle-down' effect of top-level sport: Myth or reality? A case-study of the Olympics. Aust. J. Leis. Recreat. 1994, 4, 16-24.

46. Bretherton, P.; Piggin, J.; Bodet, G. Olympic sport and physical activity promotion: The rise and fall of the London 2012 pre-event mass participation 'legacy'. Int. J. Sport Policy Politics 2016, 8, 609-624. [CrossRef]

47. Mackintosh, C.; Darko, N.; May-Wilkins, H. Unintended outcomes of the London 2012 Olympic Games: Local voices of resistance and the challenge for sport participation leverage in England. Leis. Stud. 2016, 35, 454-469. [CrossRef]

48. Müther, M.; Williamson, M.; Williamsom, L. Impact of the 2012 London Olympic and Paralympic Games on physical activity of Rheumatology patients. J. Clin. Rheumatol. 2014, 20, 376-378. [CrossRef]

49. Pappous, A.S.; Hayday, E.J. A case study investigating the impact of the London 2012 Olympic and Paralympic Games on participation in two non-traditional English sports, Judo and Fencing. Leis. Stud. 2016, 35, 668-684. [CrossRef]

50. Potwarka, L.R.; Tepylo, H.; Fortune, D.; Mair, H. Launching off but falling fast: Experiences of becoming more physically active in response to the Vancouver 2010 Olympic Winter Games. Event Manag. 2016, 20, 297-312. [CrossRef]

51. Veal, A.J.; Toohey, K.; Frawley, S. The sport participation legacy of the Sydney 2000 Olympic Games and other international sporting events hosted in Australia. J. Policy Res. Tour. Leis Events 2012, 4, 155-184. [CrossRef]

52. Frawley, S.; Cush, A. Major sport events and participation legacy: The case of the 2003 Rugby World Cup. Manag. Leis. 2011, 16, 65-76. [CrossRef]

53. Wicker, P.; Sotiriadou, P. The trickle-down effect: What population groups benefit from hosting major sport events. Int. J. Event Manag. Res. 2013, 8, 25-40.

54. Potwarka, L.R.; Snelgrove, R.; Drewery, D.; Bakhsh, J.; Wood, L. From intention to participation: Exploring the moderating role of a voucher-based event leveraging initiative. Sport Manag. Rev. 2020, 23, 302-314. [CrossRef]

55. Reis, A.C.; Sousa-Mast, F.; Gurgel, L.A. Rio 2016 and the sport participation legacies. Leis. Stud. 2014, 33, 437-453. [CrossRef]

56. Sousa-Mast, F.R.; Reis, A.C.; Gurgel, L.A.; Duarte, A.F.P.L.A. Are cariocas getting ready for the Games? Sport participation and the Rio de Janeiro 2016 Olympic Games. Manag. Leis. 2013, 18, 331-335. [CrossRef]

57. Hanstad, D.V.; Skille, E.Å. Does elite sport develop mass sport? A Norwegian case study. Scan. Sport Stud. Forum 2010, 1, 51-68.

58. Hahm, J.; Kang, T.-A.; Matsuoka, H. From inspiration to nostalgia: The football participation legacy of the 2002 FIFA World Cup Korea/Japan. Sport Soc. 2020, 23, 2055-2077. [CrossRef]

59. Ramchandani, G.M.; Coleman, R.J. The inspirational effects of three major sport events. Int. J. Event Festiv. Manag. 2012, 3, 257-271. [CrossRef]

60. Aizawa, K.; Wu, J.; Inoue, Y.; Sato, M. Long-term impact of the Tokyo 1964 Olympic Games on sport participation: A cohort analysis. Sport Manag. Rev. 2018, 21, 86-97. [CrossRef]

61. Haut, J.; Gaum, C. Does elite success trigger mass participation in table tennis? An analysis of trickle-down effects in Germany, France and Austria. J. Sport Sci. 2018, 36, 2760-2767. [CrossRef] [PubMed]

62. Misener, L.; Taks, M.; Chalip, L.; Green, B.C. The elusive 'trickle-down effect' of sport events: Assumptions and missed opportunities. Manag. Sport Leis. 2015, 20, 135-156.

63. Taks, M.; Green, B.C.; Misener, L.; Chalip, L. Evaluating sport development outcomes: The case of a medium-sized international sport event. Eur. Sport Manag. Q. 2014, 14, 213-237. [CrossRef]

64. Chalip, L.; Green, B.C.; Taks, M.; Misener, L. Creating sport participation from sport events: Making it happen. Int. J. Sport Policy Politics 2017, 9, 257-276. [CrossRef]

65. Taks, M.; Green, B.C.; Misener, L.; Chalip, L. Sport participation from sport events: Why it doesn't happen? Mark. Intell. Plan. 2018, 36, 185-198. [CrossRef]

66. Bakhsh, J.; Potwarka, L.R. Leveraging long-term sport participation from major events: The case of track cycling after the 2015 Pan Am/Parapan Am Games. Manag. Sport Leis. 2020, 25, 457-472. [CrossRef]

67. Chen, S.; Henry, I. Evaluating the London 2012 Games' impact on sport participation in a non-hosting region: A practical application of realist evaluation. Leis. Stud. 2016, 35, 685-707. [CrossRef]

68. Reis, A.C.; Frawley, S.; Hodgetts, D.; Thomson, A.; Hughes, K. Sport participation legacy and the Olympic Games: The case of Sydney 2000, London 2012, and Rio 2016. Event Manag. 2017, 21, 139-158. [CrossRef]

69. Kokolakakis, T.; Lera-López, F.; Ramchandani, G. Did London 2012 deliver a sports participation legacy? Sport Manag. Rev. 2019, 22, 276-287. [CrossRef] 
70. Ramchandani, G.; Davies, L.E.; Coleman, R.; Shibli, S.; Bingham, J. Limited or lasting legacy? The effect of non-mega sport event attendance on participation. Eur. Sport Manag. Q. 2015, 15, 93-110. [CrossRef]

71. Lovett, E.; Bloyce, D.; Smith, A. Delivering a sports participation legacy from the London 2012 Olympic and Paralympic Games: Evidence from sport development workers in Birmingham and their experiences of a double-bind. Leis. Stud. 2020, 39, 659-672. [CrossRef]

72. Macrae, E.H.R. Delivering sports participation legacies at the grassroots level: The voluntary sports clubs of Glasgow 2014. J. Sport Manag. 2016, 31, 15-26. [CrossRef]

73. Wicker, P.; Breuer, C. Scarcity of resources in German non-profit sport clubs. Sport Manag. Rev. 2011, 14, 188-201. [CrossRef]

74. Frawley, S.; Van den Hoven, P. Football participation legacy and Australia's qualification for the 2006 Football World Cup. Soccer Soc. 2015, 16, 482-492. [CrossRef]

75. Carmichael, F.; Grix, J.; Marqués, D. The Olympic legacy and participation in sport: An interim assessment of Sport England's Active People Survey for sports studies research. Int. J. Sport Policy Politics 2013, 5, 229-244. [CrossRef]

76. Storm, R.K.; Nielsen, C.G.; Jakobsen, T.G. Can international elite sport success trickle down to mass sport participation? Evidence from Danish team handball. Eur. J. Sport Sci. 2018, 18, 1139-1150. [CrossRef]

77. Darko, N.; Mackintosh, C. 'Don't you feel bad watching the Olympics, watching us?' A qualitative analysis of London 2012 Olympics influence on family sports participation and physical activity. Qual. Res. Sport Exerc. Health 2016, 8, 45-60. [CrossRef]

78. Hargreaves, J. Heroines of Sport. The Politics of Difference and Identity; Routledge: Oxfordshire, UK, 2000.

79. Malchrowicz-Mosko, E.; Poczta, J.; Adamczewska, K. The potential of non-mega sporting events for the promotion of physical activity among inactive supporters at the Poznan half marathon: A case study. Int. J. Environ. Res. Public Health 2019, 16, 4193. [CrossRef]

80. Ramchandani, G.; Coleman, R.J.; Bingham, J. Sport participation behaviours of spectators attending major sports events and event induced attitudinal changes towards sport. Int. J. Event Festiv. Manag. 2017, 8, 121-135. [CrossRef]

81. Teare, G.; Potwarka, L.R.; Snelgrove, R.; Drewery, D. Inspiring participation in track cycling: Exploring the role of spectator characteristics and event experiences. Event Manag. 2020, in press. [CrossRef]

82. Thrash, T.M.; Elliot, A.J. Inspiration as a psychological construct. J. Pers. Soc. Psychol. 2003, 84, 871-889. [CrossRef] [PubMed]

83. Mutter, F.; Pawlowski, T. The causal effect of professional sports on amateur sport participation-An instrumental variable approach. Int. J. Sport Financ. 2014, 9, 172-188.

84. Mutter, F.; Pawlowski, T. The monetary value of the demonstration effect of professional sports. Eur. Sport Manag. Q. 2014, 14, 129-152. [CrossRef]

85. Funk, D.; Jordan, J.; Ridinger, L.; Kaplanidou, K. Capacity of mass participation sport events for the development of activity commitment and future exercise intention. Leis. Sci. 2011, 33, 250-268. [CrossRef]

86. Wicker, P.; Prinz, J.; von Hanau, T. Estimating the value of national sporting success. Sport Manag. Rev. 2012, 15, 200-210. [CrossRef]

87. Stigler, G.; Becker, G.S. De gustibus non est disputandum. Am. Econ. Rev. 1977, 67, 76-90. [CrossRef]

88. Ahlfeldt, G.; Maennig, W. Voting on a NIMBY facility: Proximity cost of an "iconic" stadium. Urban Aff. Rev. 2012, 48, 205-237. [CrossRef]

89. Weimar, D.; Rocha, C.M. Does distance matter? Geographical distance and domestic support for mega sports events. J. Sports Econ. 2017, 20, 286-313. [CrossRef]

90. Jiang, K.; Potwarka, L.R.; Ramchandani, G.; Coleman, R. Beyond the host nation: An exploration of trickle-down effects in the "hometowns" of Canadian athletes who medaled at London 2012. In Proceedings of the North American Society for Sport Management, New Orleans, LA, USA, 29 May-1 June 2019; p. 24.

91. Storm, R.K.; Holum, M.L. Does local sporting success affect sport participation? An examination of Danish professional soccer's effect on club membership. Eur. Sport Manag. Q. 2020, in press. [CrossRef]

92. Wicker, P.; Frick, B. Recruitment and retention of referees in nonprofit sport organizations: The trickle-down effect of role models. Voluntas 2016, 27, 1304-1322. [CrossRef] 